\title{
Skin markers and the prediction of intraabdominal adhesion during second Cesarean delivery
}

\author{
Zainab Abdul Ameer Jaafar ${ }^{1}$, Reshed Zeki Obeid ${ }^{2}$, Dina Akeel Salman ${ }^{1}$ \\ ${ }^{1}$ Department of Obstetrics and Gynecology, College of Medicine, Al-Mustansiriya University, Baghdad, Iraq \\ ${ }^{2}$ Department of Obstetrics and Gynaecology, College of Medicine, Al-Anbar University, Ramadi, Iraq
}

\begin{abstract}
Objectives: The aim of the present study has been to examine skin scar characteristics and striae gravidarum, considering the reliability of each for predicting adhesions in repeat Caesarean sections. Material and methods: A cross-sectional study was done over a period of two years. One hundred pregnant women were invited to participate in the study. Preoperatively, abdominal scar features (according to the scar's appearance) and stria gravidarum were both recorded.Then, at the time of surgery, intraabdominal adhesions weregraded according to the modified Nair's classification. Results: Among the skin markers, abdominal scar width $(p=0.001)$, depressed scar $(p=0.002)$ and striae colour grading ( $p=0.0183$ ) were found to have significant associations with intraabdominal adhesions; yet all were of low validity. Conclusions: Despite growing interest in the use of skin markers in the prediction of intraabdominal adhesions at the time of repeat CS, the present study demonstrates that these markers may not be reliable.
\end{abstract}

Key words: adhesions; caesarean section; abdominal scarf; striae gravidarum

Ginekologia Polska 2019; 90, 6: 325-330

\section{INTRODUCTION}

Cesarean section (CS) is one of the most common operations done in the obstetric ward, and its usage is rapidly rising [1]. In the United States, the rate of Cesarean delivery during the last twenty-five years has risen to $30 \%$ of all deliveries; and in the last ten years, it has become the fifth-most-frequent surgical procedure performed in the U.S [2]. According to the annual statistical report published by the Iraqi Ministry of Health in 2017, the rate of Cesarean section deliveries in Iraq was 33.2\% [3]. This expansion has been attributed to several factors: an increase in CS performed on maternal demand; a decrease in the trial of the scar from a previous CS; and a rise in hypertension, diabetes mellitus, and other chronic diseases [4]. With the increasing rate of this type of delivery, the drawbacks of the procedure have also increased, including both immediate and long term complications [5]. Intraabdominal adhesions are known complications of CS, leading to patient morbidity and creating problems during the next CS, including difficulty in gaining entrance into the abdominal cavity and injury to the pelvic and abdominal organs [6]. The anticipation of adhesions is essential as the surgeon chooses the place of operation, and it plays an important role in the pre-operative assessment aimed at preventing intraoperative complications [2]. Stretch-lines, or striae gravidarum, are one of the physiological changes that occur in the skin of pregnant women. These striae may present in any site but are especially common in the abdomen, breast, leg, and buttocks. The disruptions represented by striae vary from one female to another due to genetic differences and other risk factors [7]. The central reason for the appearance of striae gravidarum is unclear, but estrogen, a hormone that increases during pregnancy, plays an important role in the development of skin stretch marks [8]. In comparison with healthy skin, the striae have been found to have more than double the number of estrogen receptors than regular skin, as well as much higher numbers of both androgen and glucocorticoid receptors [9]. Any operation will result in some tissue damage, and the body will respond to this damage by increasing the extracellular permeability and aggregation of macrophage and fibroblast forming a fibrin matrix. After nine days, this matrix will break by fibrinolysis; if this processing does not occur, the fibroblast produces collagen and this will, in turn, form an adhesion [10]. It has been 
determined that collagen plays a major part in the progress of striae gravidarum, and that stretch lines and adhesions have the same pathogenesis [6]. The same thing is true for the abdominal scar, as the wound-healing mechanism is the same as that of adhesion formation since the skin and the peritoneum both respond to injury in the same way [11].

\section{Objectives}

The aim of the current work is to evaluate the association of abdominal scar characteristics and the severity and color grading of striae gravidarum with intraabdominal adhesions after primary CS, and to determine whether these markers are valid regarding the prediction of the severity of adhesions.

\section{MATERIAL AND METHODS}

The present study is a cross-sectional study, done in Al-Yarmouk teaching hospital, from March 1, 2016, to March 1,2018 . The local ethics committee of the medical college at Al-Mustansiryia University approved the study protocol. All participants gave informed consent before being included in the study. A sample of 100 pregnant women, all at 37 or more weeks of gestation and admitted to our Labor Ward for elective CS, were invited to participate in the study. The operative notes of the previous CS were reviewed, taking into consideration that the same technique was applied to all women. In order to reduce bias, women selected for the study had all been previously operated on in Al-Yarmouk teaching hospital, and all with the same procedure, which used a double-layer uterine closure, no closure of the peritoneum, and closure of the rectus muscle. The latter was closed using Nylon suture materials and the skin was closed by continuous subcuticular sutures. In addition, all of the women had uneventful intraoperative and postoperative periods, with the use of prophylactic antibiotics during both periods. Those included into the study had singleton pregnancies, had gestated to term (37-41 weeks), had one previous elective CS for Cephalopelvic disproportion (CPD) that was done two years ago by the same surgeon (the author), and did not have any previous striae prior to pregnancy. All the participants were of similar skin colour, in that those of type 3 (light brown skin) and type 4 (moderate brown skin), according to modified Fitzpatrick scale [12] were chosen. Those excluded from the study were women with midline incisions, those having had previous pelvic surgery other than CS, those with a history of wound infection following the first CS, and those with either meconium-stained liquor or with placenta accrete. Also excluded from the study were women having a past history of pelvic inflammatory diseases, endometriosis, or Cushing's syndrome; those with a history of long-term corticosteroid use; those with gestational diabetes, macrosomia, or polyhydramnios; and those with any personal or family history of keloid.
All women underwent a detailed demographic data survey that included age, smoking status, and body mass index (BMI) on admission for delivery, with all data being recorded and compared among all groups. For the purpose of assessing the severity of the striae gravidarum, the Davey scoring system was applied; thus the number of striae per each of the presumed four quadrants [13] was counted. If the skin was clear, the score was 0 ; a score of 1 was given if the number of striae per quadrant was 1-3; and if the number of striae was $\leq 4$, then the score was 2 . The total striae score was calculated by the summation of the scores of the four quadrants: a total score of 0 was termed "no striae"; a total score of 1-2 was termed "mild striae"; and a score of 3-8 was termed "severe striae".

Abdominal inspection was performed on each woman, and striae of all colors (reddish, glistening, and silvery lines) were taken into account regardless of the severity, and thus subdivided into striae rubra and striae alba. According to their appearance, the CS scars were classified as flat, elevated, or depressed (partially depressed scars were also considered). The colour of the scar was compared to the surrounding skin and subdivided into those of the same colour, those hyperpigmented, and those that were hypopigmented. Grading of adhesions was done intraoperatively, using the modified Nair'/s classification, [14] thus classified into the categories of no adhesion, filmy, moderate, or cohesive adhesions.

The statistical analysis was performed by Statistical Package for Social Sciences (SPSS 25)* desidned foe data analysis. Categorical data were represented by frequencies and percentages. Association between the variable were measured using Pearson's chi-squared test. Continuous data were represented by mean and standard deviation. The differences between groups for continuous data (age and $\mathrm{BMI}$ ) were measured using the Analysis of Variances (ANOVA) test. The receiver operator curve wasused to calculate validity parameters of scar width and abdominal scar length in prediction of adhesions. An alpha level $\leq 0.05$ was considered significant.

*IBM Corp. Released 2017. IBM SPSS Statistics for Windows, Version 25.0. Armonk, NY: IBM Corp.

\section{RESULTS}

Of the total 100 women who participated in the study, 24 were found to have no adhesions, 23 had filmy adhesions, 25 had moderate adhesions, and 28 had cohesive adhesions. Moderate to severe adhesions accounted for $53 \%$ of the cases. Among these four groups, no significant difference was found regarding various demographic factors, including age, smoking status, and BMI. (Tab. 1).

Regarding the scar features, scar width has a significant association with the severity of adhesions in that the wider 


\begin{tabular}{|c|c|c|c|c|c|c|c|}
\hline \multirow{2}{*}{\multicolumn{2}{|c|}{ Variable }} & \multicolumn{4}{|c|}{ Adhesion } & \multirow[b]{2}{*}{ Total $\mathbf{n}$} & \multirow[b]{2}{*}{ P-value } \\
\hline & & $\begin{array}{c}\text { No } \\
n=24\end{array}$ & $\begin{array}{l}\text { Filmy } \\
n=23\end{array}$ & $\begin{array}{c}\text { Moderate } \\
n=25\end{array}$ & $\begin{array}{l}\text { Cohesive } \\
n=\mathbf{2 8}\end{array}$ & & \\
\hline \multicolumn{2}{|c|}{ Age (years), Mean \pm SD } & $28 \pm 7$ & $26.4 \pm 5.6$ & $29.8 \pm 7.7$ & $28.6 \pm 5.9$ & $28.2 \pm 6.6$ & $0.354^{\mathrm{a}}$ \\
\hline \multirow[t]{2}{*}{ Smoking, No. (\%) } & Yes & $\begin{array}{c}8 \\
(47.1 \%)\end{array}$ & $\begin{array}{c}3 \\
(17.6 \%)\end{array}$ & $\begin{array}{c}3 \\
(17.6 \%)\end{array}$ & $\begin{array}{c}3 \\
(17.6 \%)\end{array}$ & $\begin{array}{c}17 \\
(100 \%)\end{array}$ & \multirow[t]{2}{*}{$0.111^{x}$} \\
\hline & No & $16(19.3 \%)$ & $20(24.1 \%)$ & $22(26.5 \%)$ & $25(30.1 \%)$ & $83(100 \%)$ & \\
\hline \multicolumn{2}{|c|}{ BMI $\left(\mathrm{kg} / \mathrm{m}^{2}\right)$, Mean \pm SD } & $27 \pm 5$ & $25.7 \pm 4.8$ & $28.2 \pm 4.7$ & $25.9 \pm 4.3$ & $26.7 \pm 4.7$ & $0.227^{a}$ \\
\hline
\end{tabular}

SD — standard deviation; ${ }^{\mathrm{x}}$ chi-squared test; ${ }^{\text {aANOVA test }}$

\begin{tabular}{|c|c|c|c|c|c|c|c|}
\hline \multirow{2}{*}{\multicolumn{2}{|c|}{ Variables }} & \multicolumn{4}{|c|}{ Adhesions } & \multirow[b]{2}{*}{ Total } & \multirow[b]{2}{*}{ P-value } \\
\hline & & \multirow{2}{*}{$\begin{array}{c}\begin{array}{c}\text { No } \\
\mathbf{N}=\mathbf{2 4}\end{array} \\
13 \\
(46.43 \%)\end{array}$} & \multirow{2}{*}{$\begin{array}{c}\text { Filmy } \\
\mathbf{N}=\mathbf{2 3} \\
6 \\
(21.43 \%)\end{array}$} & \multirow{2}{*}{$\begin{array}{c}\text { Moderate } \\
\qquad \begin{array}{c}\mathbf{N}=\mathbf{2 5} \\
5 \\
(17.86 \%)\end{array}\end{array}$} & \multirow{2}{*}{$\begin{array}{c}\text { Cohesive } \\
\begin{array}{c}\mathbf{N}=\mathbf{2 8} \\
4 \\
(14.29 \%)\end{array}\end{array}$} & & \\
\hline \multirow{3}{*}{$\begin{array}{l}\text { Scar } \\
\text { appearance, } \\
\text { No. (\%) }\end{array}$} & Flat & & & & & $\begin{array}{c}28 \\
(100 \%)\end{array}$ & \multirow{3}{*}{$0.0028^{* x}$} \\
\hline & Hypertrophied & $\begin{array}{c}3 \\
(33.33 \%)\end{array}$ & $\begin{array}{c}3 \\
(33.33 \%)\end{array}$ & $\begin{array}{c}2 \\
(22.22 \%)\end{array}$ & $\begin{array}{c}1 \\
(11.11 \%)\end{array}$ & $\begin{array}{c}9 \\
(100 \%)\end{array}$ & \\
\hline & Depressed & $\begin{array}{c}8 \\
(12 \%)\end{array}$ & $\begin{array}{c}14 \\
(22.22 \%)\end{array}$ & $\begin{array}{c}18 \\
(28.57 \%)\end{array}$ & $\begin{array}{c}23 \\
(36.51 \%)\end{array}$ & $\begin{array}{c}63 \\
(100 \%)\end{array}$ & \\
\hline \multirow{3}{*}{$\begin{array}{l}\text { Scar colour, } \\
\text { No. }(\%)\end{array}$} & No change & $11(20.8 \%)$ & $11(20.8 \%)$ & $16(30.2 \%)$ & $15(28.3 \%)$ & $53(100 \%)$ & \multirow{3}{*}{$0.492^{x}$} \\
\hline & Hypo-pigmented & $6(27.3 \%)$ & $8(36.4 \%)$ & $4(18.2 \%)$ & $4(18.2 \%)$ & $22(100 \%)$ & \\
\hline & Hyper-pigmented & $7(28 \%)$ & $4(16 \%)$ & $5(20 \%)$ & $9(36 \%)$ & $25(100 \%)$ & \\
\hline \multicolumn{2}{|c|}{ Scar width $(\mathrm{cm})$, Mean \pm SD } & $1.9 \pm 0.2$ & $1.9 \pm 0.3$ & $2.1 \pm 0.2$ & $2.2 \pm 0.3$ & $2 \pm 0.3$ & $0.001 * a$ \\
\hline
\end{tabular}

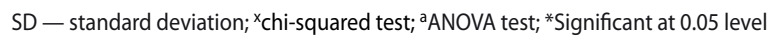

\begin{tabular}{|c|c|c|c|c|c|c|c|}
\hline \multirow[b]{2}{*}{ Variables } & & \multicolumn{4}{|c|}{ Adhesions } & \multirow[b]{2}{*}{ Total } & \multirow[b]{2}{*}{ P-value } \\
\hline & & $\begin{array}{c}\text { No } \\
n=24\end{array}$ & $\begin{array}{l}\text { Filmy } \\
n=23\end{array}$ & $\begin{array}{c}\text { Moderate } \\
n=25\end{array}$ & $\begin{array}{c}\text { Cohesive } \\
\mathbf{n}=\mathbf{2 8}\end{array}$ & & \\
\hline \multirow{3}{*}{$\begin{array}{l}\text { Severity of the } \\
\text { striae, No. (\%) }\end{array}$} & No & $\begin{array}{c}6 \\
(27.27 \%)\end{array}$ & $\begin{array}{c}7 \\
(31.82 \%)\end{array}$ & $\begin{array}{c}5 \\
(22.73 \%)\end{array}$ & $\begin{array}{c}4 \\
(18.18 \%)\end{array}$ & 22 (100\%) & \multirow{3}{*}{$0.4054^{x}$} \\
\hline & Mild & $8(24.2 \%)$ & $6(18.2 \%)$ & 12 (36.4\%) & $7(21.2 \%)$ & 33 (100\%) & \\
\hline & Severe & $10(22.2 \%)$ & $8(17.8 \%)$ & $10(22.2 \%)$ & 17 (37.8\%) & 45 (100\%) & \\
\hline \multirow{2}{*}{$\begin{array}{l}\text { Stria color grading, } \\
\text { No. }(\%)\end{array}$} & Rubra & $\begin{array}{c}5 \\
(15.62 \%)\end{array}$ & $\begin{array}{c}6 \\
(18.75 \%)\end{array}$ & $\begin{array}{c}5 \\
(15.62 \%)\end{array}$ & $\begin{array}{c}16 \\
(50 \%)\end{array}$ & $\begin{array}{c}32 \\
(100 \%)\end{array}$ & \multirow{2}{*}{$0.0183^{* x}$} \\
\hline & Alba & $\begin{array}{c}13 \\
(28.26 \%)\end{array}$ & $\begin{array}{c}10 \\
(21.74 \%)\end{array}$ & $\begin{array}{c}15 \\
(32.61 \%)\end{array}$ & $\begin{array}{c}8 \\
(17.39 \%)\end{array}$ & $\begin{array}{c}46 \\
(100 \%)\end{array}$ & \\
\hline
\end{tabular}

SD — standard deviation; ${ }^{x}$ chi-squared test; *Significant at 0.05 level

the scar the more likely adhesions are to be suspected ( $p$-val$\mathrm{ue}=0.001$ ). At the same time, scar appearance was also significantly associated with adhesion ( $p$-value $=0.0028$ ), while scar colour does not have any association ( $p$-value $=0.492)($ Tab. 2$)$.

Table 3 shows that there is no significant association between the striae severity and the possibility of adhesions ( $p$-value $=0.492$ ), while the striae color grading was found to be associated with the adhesions ( $p$-value $=0.0182$ ).
In order to assess the validity of scar width as a predictor for adhesion, the Receiver operator curve was applied. It was found that, at a width of $0.697 \mathrm{~cm}$, the sensitivity (SN) was $49.1 \%$, while the specificity (SP) was $80.9 \%$ (as shown in Table 4 and Figure 1).

To assess the validity of the striae color grading in prediction of adhesions, those with striae $(\mathrm{N}=78)$ were either red (rubra) $(\mathrm{N}=32)$ or glistening to silvery (alba) $(\mathrm{N}=46)$, 


\begin{tabular}{|c|c|c|c|}
\hline \multicolumn{3}{|c|}{ Table 4. The validity of scar width in the prediction of adhesions } \\
\hline \multirow{2}{*}{ Area } & P-value & \multicolumn{2}{|c|}{$\begin{array}{c}\text { Asymptotic } 95 \% \\
\text { Confidence Interval }\end{array}$} \\
\cline { 2 - 4 } & Lower Bound & Upper Bound \\
\hline 0.697 & $0.001^{*}$ & 0.595 & 0.798 \\
\hline Sensitivity & Specificity & PPV & NPV \\
\hline $49.1 \%$ & $80.9 \%$ & $74.3 \%$ & $58.5 \%$ \\
\hline
\end{tabular}

*Significantly different from expected AUC

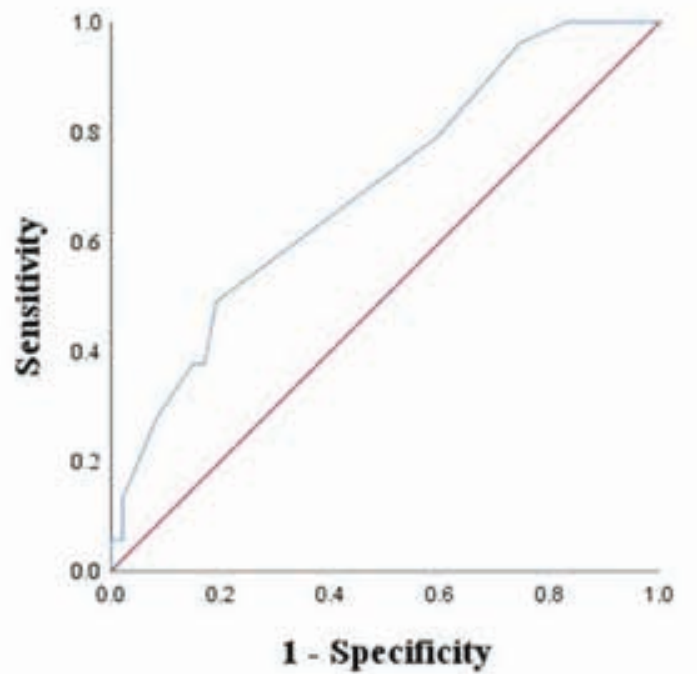

Figure 1. Receiver operator curve for validity parameters of scar width in prediction of adhesion

while the adhesions were categorized into two groups: No striae or filmy ( $\mathrm{N}=34)$, and moderate-to-cohesive ( $\mathrm{N}=44)$. The sensitivity was $47.7 \%$ and the specificity was $67.6 \%$ (Tab. 5).

For assessment of the validity of abdominal scar features in predicting intraabdominal adhesions, patients were categorized into two groups: depressed scars $(N=63)$ or not depressed scars $(\mathrm{N}=37)$. They were then further classified into the categories adhesion or no adhesion. The sensitivity was $77.35 \%$ and the specificity was $53.19 \%$ (Tab. 6).

\section{DISCUSSION}

With the increased incidence of CS deliveries and the complications resulting from the procedure, specifically intraperitoneal adhesions, many authors have tried to develop a simple, noninvasive way to predict this complication. Prediction of adhesions using skin markers was one of these methods, a subject which has received attention in recent years.

The incidence of adhesions at the time of the second laparotomy was found by some authors to be as high as 93\% [10]. With the exclusion of filmy adhesions, moderate to severe adhesions were found to be $53 \%$ in the current study, while Herzberger et al. reported that significant adhesions after primary CS were around 43\%; they also stated that the personal impact on adhesion formation was more important than the number of CS [15].

It is well known that the closure versus non-closure of the peritoneum has long been linked to adhesion formation in many previous studies, always with a great deal of debate [16]. Shiliro et al [17] studied factors influencing adhesion formation after primary CS; they recommended that peritoneal and/or rectus muscle closure at Cesarean delivery (CD) is to be performed as a routine measure that is both safe and cost-effective, in order to reduce subsequent adhesions [17]. In a systemic review of 29 trials published by Bamigboye et al [18] limited and inconsistent evidence was found regarding the relationship between adhesion formation and closure versus non-closure, while the non-closure technique was associated with shorter surgical time [18]

Neither of the demographic factors in this study was found to be associated with the severity of adhesions. This is similar to the results found by Taylan et al. [2] Stocker et al. [11] and Çim et al. [19].

Table 5. The validity of striae color grading for prediction of adhesions

\begin{tabular}{|l|l|c|c|c|c|c|c|c|}
\hline Adhesions & No striae or filmy & Moderate to cohesive & Total & SN & SP & PPV & NPV \\
\hline $\begin{array}{l}\text { Striae color } \\
\text { grading }\end{array}$ & Rubra & 11 & 21 & 32 & & & & \\
\hline & Alba & 23 & 23 & 46 & $47.7 \%$ & $67.6 \%$ & $65.6 \%$ & $50.0 \%$ \\
\hline & Total & 34 & 44 & 78 & & & & \\
\hline
\end{tabular}

Table 6. The validity of abdominal scar features for prediction of adhesion

\begin{tabular}{|c|c|c|c|c|c|c|c|c|}
\hline \multicolumn{2}{|l|}{ Adhesions } & Present & Not present & Total & SN & SP & PPV & NPV \\
\hline \multirow{3}{*}{ Scar features } & Depressed & 41 & 22 & 63 & \multirow{3}{*}{$77.35 \%$} & \multirow{3}{*}{$53.19 \%$} & \multirow{3}{*}{$65.07 \%$} & \multirow{3}{*}{$67.56 \%$} \\
\hline & Not depressed & 12 & 25 & 37 & & & & \\
\hline & Total & 53 & 47 & 100 & & & & \\
\hline
\end{tabular}


The current study attempted to apply two skin markers together, each of which had previously been taken by other researchers as separate factors. The study tried to assess their validity as a pair in the prediction of adhesions following primary CS.

Many of the abdominal scar features were considered to have an association with adhesions by many authors, such as Çim et al., who found that depressed scars with hypopigmentation are associated with adhesions [19]. Pergialiotis et al. [20] undertook a meta-analysis of several observational studies and concluded that depressed scars were positively associated with intra-abdominal adhesions, while flat scars were predictive of the absence of adhesions. In spite of that, the authors noted that the number of published studies is small, and thus recommended further research to confirm their findings [20]. In fact, the current study agrees with the above-mentioned work in finding that a depressed scar is significantly associated with adhesions (with $\mathrm{SN}=77.35 \%$ and SP $=53.19 \%$ ); however, this study did not find any association between the scar color and the severity of adhesions. On the other hand, this study did find a significant association between adhesion and scar width, similar to the results of Kahyaoglu et al. [21] who also agree with our results in that the scar colour changes are not associated with adhesions. According to the current results, the scar width has a positive predictive value (PPV) of $74.3 \%$ but an negative predictive value (NPV) of only $58.5 \%$ in the prediction of adhesions.

Prediction of adhesions using striae gravidarum has received attention in the work of many authors in the recent years. The severity of striae gravidarum was related to intraabdominal adhesions according to both Dogan et al. [6] and Gungor et al. [13], contrary to the results of the present study. On the other hand, Celik et al. revealed that striae gravidarum are associated with abdominal scar characteristics rather than being associated with intraabdominal adhesions [7], thus agreeing, at least in part, with the present study. This study revealed a significant association between striae color grading (striae alba) and the severity of adhesion, suggesting that the type of striae rather than its severity is associated with intraabdominal adhesions. The colour change of striae gravidarum from striae rubra to striae alba is known to be related to its stage of maturation [22]; and as this process needs time ranging from months to years [9], it might be supposed that the more rapid the striae changes, the more the liability for adhesion formation within a fixed period of time. In spite of that, this association is of low sensitivity and specificity, and thus lacks validity for prediction of adhesion presence at the time of subsequent CS.

One of the main limitations of the current study was the small size of the study group. This might be attributed to the restricted criteria used in participant selection, namely the interpregnancy interval and the shade of complexion, though these criteria should not be surprising since the darkest skin shades are associated with a higher risk of scar hypertrophy and keloid, while these risks are absent in those with albinism [23]. Striae gravidarum are also known to be more severe in those with darker skin [24]. Therefore, it was necessary to choose those with more convergent skin colour in order to reduce bias.

\section{CONCLUSIONS}

Despite increasing interest in the use of skin markers in the prediction of adhesions (whether these markers are abdominal scar features or striae gravidarum), these parameters are of low validity at present. It is, therefore, recommended that further studies will be necessary in order to prove the current conclusions.

\section{Acknowledgement}

The Authors would like to thank all the women who participated in the study.

\section{REFERENCES}

1. Ye J, Zhang J, Mikolajczyk R, et al. Association between rates of caesarean section and maternal and neonatal mortality in the 21 st century: a worldwide population-based ecological study with longitudinal data. BJOG. 2016; 123(5): 745-753, doi: 10.1111/1471-0528.13592, indexed in Pubmed: 26331389.

2. Taylan E, Akdemir A, Ergenoglu AM, et al. Can We Predict the Presence and Severity of Intra-Abdominal Adhesions before Cesarean Delivery. Gynecol Obstet Invest. 2017; 82(6): 521-526, doi: 10.1159/000454767, indexed in Pubmed: 27997914.

3. The Iraqi ministry of health and environment. Annual statistic report [Internet]. Iraqi national library and archieves. 2017. p. 49. https://moh. gov.iq/index.php?name=News\&file=article\&sid=6291.

4. Nuamah MA, Browne JL, Öry AV, et al. Prevalence of adhesions and associated postoperative complications after cesarean section in Ghana: a prospective cohort study. Reprod Health. 2017; 14(1): 143, doi: 10.1186/s12978-017-0388-0, indexed in Pubmed: 29096649.

5. van der Voet LF, Jordans IPM, Brölmann HAM, et al. Changes in the Uterine Scar during the First Year after a Caesarean Section: A Prospective Longitudinal Study. Gynecol Obstet Invest. 2018; 83(2): 164-170, doi: $10.1159 / 000478046$, indexed in Pubmed: 28957798.

6. Dogan A, Ertas IE, Uyar I, et al. Preoperative Association of Abdominal Striae Gravidarum with Intraabdominal Adhesions in Pregnant Women with a History of Previous Cesarean Section: a Cross-sectional Study. Geburtshilfe Frauenheilkd. 2016; 76(3): 268-272, doi: 10.1055/s-0042101545, indexed in Pubmed: 27065488.

7. Celik EY, Ersoy AO, Ersoy E, et al. Is Striae Gravidarum related to Cesarean Scar and Peritoneal Adhesions? Pak J Med Sci. 2018; 34(3): 568-573, doi: $10.12669 /$ pjms.343.14288, indexed in Pubmed: 30034417.

8. Kasielska-Trojan A, Sobczak M, Antoszewski B. Risk factors of striae gravidarum. Int J Cosmet Sci. 2015; 37(2): 236-240, doi: 10.1111/ics.12188, indexed in Pubmed: 25440082

9. Farahnik B, Park K, Kroumpouzos G, et al. Striae gravidarum: Risk factors, prevention, and management. Int JWomens Dermatol. 2017; 3(2): 77-85, doi: 10.1016/i.iiwd.2016.11.001 indexed in Pubmed: 28560300.

10. Okabayashi $\mathrm{K}$, Ashrafian $\mathrm{H}$, Zacharakis $\mathrm{E}$, et al. Adhesions after abdominal surgery: a systematic review of the incidence, distribution and severity. Surg Today. 2014; 44(3): 405-420, doi: 10.1007/s00595-013-0591-8, indexed in Pubmed: 23657643.

11. Stocker LJ, Glazebrook JE, Cheong YC. Are skin scar characteristics associated with the degree of pelvic adhesions at laparoscopy? Fertil Steril. 2014; 101(2): 501-505, doi: 10.1016/j.fertnstert.2013.10.026, indexed in Pubmed: 24289993

12. Walsh $S$, Chaitanya $L$, Breslin $K$, et al. Global skin colour prediction from DNA. Hum Genet. 2017; 136(7):847-863, doi:10.1007/s00439-017-1808-5, indexed in Pubmed: 28500464. 
13. Cakir Gungor AN, Oguz S, Hacivelioglu S, et al. Predictive value of striae gravidarum severity for intraperitoneal adhesions or uterine scar healing in patients with previous caesarean delivery. J Matern Fetal Neonatal Med. 2014; 27(13): 1312-1315, doi: 10.3109/14767058.2013.856876, indexed in Pubmed: 24134618.

14. Khorshidi HR, Kasraianfard A, Derakhshanfar A, et al. Evaluation of the effectiveness of sodium hyaluronate, sesame oil, honey, and silver nanoparticles in preventing postoperative surgical adhesion formation. An experimental study. Acta Cir Bras. 2017; 32(8): 626-632, doi: 10.1590/s0102865020170080000004 , indexed in Pubmed: 28902938.

15. Herzberger $\mathrm{EH}$, Alon $\mathrm{H}$, Hershko-Klement $\mathrm{A}$, et al. Adhesions at repeat cesarean delivery: is there a personal impact? Arch Gynecol Obstet. 2015;292(4): 813-818, doi: 10.1007/s00404-015-3718-x, indexed in Pubmed: 25877223.

16. Lyell D, Caughey A, Hu E, et al. Rectus muscle and visceral peritoneum closure at cesarean delivery and intraabdominal adhesions. Am J Obstet Gynecol. 2012; 206(6): 515.e1-515.e5, doi: 10.1016/j.ajog.2012.02.033.

17. Schiliro A, Muscat J, Calixte R, et al. 515: Factors influencing adhesion formation after primary cesarean delivery. Am J Obstet Gynecol. 2016; 214(1): S279-S280, doi: 10.1016/j.ajog.2015.10.559.

18. Bamigboye AA, Hofmeyr GJ. Closure versus non-closure of the peritoneum at caesarean section: short- and long-term outcomes. Cochrane Database Syst Rev. 2014(8): CD000163, doi: 10.1002/14651858. CD000163.pub2, indexed in Pubmed: 25110856.
19. Çim N, Elçi E, Güneş Elçi G, et al. Are the skin scar characteristics and closure of the parietal peritoneum associated with pelvic adhesions? Turk J Obstet Gynecol. 2018; 15(1): 28-32, doi: 10.4274/tjod.55491, indexed in Pubmed: 29662713.

20. Pergialiotis V, Frountzas M, Siotos C, et al. Cesarean wound scar characteristics for the prediction of pelvic adhesions: a meta-analysis of observational studies. J Matern Fetal Neonatal Med. 2017; 30(4): 486-491, doi: 10.1080/14767058.2016.1176135, indexed in Pubmed: 27072887.

21. Kahyaoglu I, Kayikcioglu F, Kinay $T$, et al. Abdominal scar characteristics: do they predict intra-abdominal adhesions with repeat cesarean deliveries? J Obstet Gynaecol Res. 2014; 40(6): 1643-1648, doi: 10.1111/jog.12429, indexed in Pubmed: 24888928.

22. Bogdan C, lurian S, Tomuta I, et al. Improvement of skin condition in striae distensae: development, characterization and clinical efficacy of a cosmetic product containing seed oil and resin extract. Drug Des Devel Ther. 2017; 11:521-531, doi: 10.2147/DDDT.S128470, indexed in Pubmed: 28280300.

23. Ogawa R. Keloid and Hypertrophic Scars Are the Result of Chronic Inflammation in the Reticular Dermis. Int J Mol Sci. 2017; 18(3), doi: 10.3390/ijms18030606, indexed in Pubmed: 28287424.

24. Jeon $C$, Agbai O, Butler $D$, et al. Dermatologic conditions in patients of color who are pregnant. Int J Womens Dermatol. 2017; 3(1): 30-36, doi: 10.1016/j.jiwd.2017.02.019, indexed in Pubmed: 28492052. 